\title{
Gradhiva
}

\section{Barbara Glowczewski et Rosita Henry (éd.), Le Défi indigène, entre spectacle et politique}

Montreuil, Aux lieux d'être, 2007, 363 p.

\section{Christian Coiffier}

\section{(2) OpenEdition}

\section{Journals}

Édition électronique

URL : http://journals.openedition.org/gradhiva/1142

DOI : $10.4000 /$ gradhiva. 1142

ISSN : 1760-849X

\section{Éditeur}

Musée du quai Branly Jacques Chirac

Édition imprimée

Date de publication : 15 mai 2008

Pagination : 166-168

ISBN : 978-2-915133-86-8

ISSN : 0764-8928

\section{Référence électronique}

Christian Coiffier, « Barbara Glowczewski et Rosita Henry (éd.), Le Défi indigène, entre spectacle et politique », Gradhiva [En ligne], 7 | 2008, mis en ligne le 10 décembre 2008, consulté le 21 septembre 2020. URL : http://journals.openedition.org/gradhiva/1142 ; DOI : https://doi.org/10.4000/gradhiva. 1142

Ce document a été généré automatiquement le 21 septembre 2020

(c) musée du quai Branly 


\title{
Barbara Glowczewski et Rosita Henry (éd.), Le Défi indigène, entre spectacle et politique
}

Montreuil, Aux lieux d'être, 2007, 363 p.

\author{
Christian Coiffier
}

\section{RÉFÉRENCE}

Barbara Glowczewski et Rosita Henry (éd.), Le Défi indigène, entre spectacle et politique.Montreuil, Aux lieux d'être, 2007, 363 p.

1 Le 13 février 2008, le Premier ministre australien Kevin Rudd prononce devant le Parlement de Canberra un discours historique dans lequel il demande pardon aux populations aborigènes pour les mauvais traitements qu'elles ont pu subir depuis les débuts de la colonisation. C'est dans ce nouveau contexte des relations entre le gouvernement australien et les communautés aborigènes locales que paraît ce douzième ouvrage de la collection «Mondes contemporains" dirigée par Julien Ténédos, coordonné par Barbara Glowczewski et Rosita Henry. Ce livre se trouve ainsi sous le feu de l'actualité puisque les articles qui le composent présentent l'engagement de plusieurs peuples autochtones d'Océanie et d'Asie, particulièrement des Aborigènes australiens, dans leur tentative de transposer leur culture sur la scène de l'art international et sur le plan du politique. Les auteurs sont tous des ethnologues de terrain, ils analysent les diverses stratégies de ces peuples visant à faire reconnaître la spécificité de leur culture au sein d'un monde de plus en plus globalisé, mais où les États-nation continuent souvent d'opprimer culturellement certaines de leurs communautés minoritaires.

2 L'ouvrage se présente sous la forme de douze chapitres regroupés en deux grandes parties traitant, pour la première, du paradigme des Aborigènes d'Australie et, pour la seconde, de différents types d'engagement de communautés autochtones d'Océanie et 
d'Asie. Barbara Glowczewski s'est chargée de l'introduction et Rosita Henry de la conclusion. Des photographies en noir et blanc placées entre chacun des chapitres ainsi qu'une riche bibliographie et une série de notices présentant chacun des auteurs viennent compléter ce volume.

3 Barbara Glowczewski a déjà publié plusieurs ouvrages sur les Aborigènes australiens. Elle s'intéresse depuis plusieurs années aux stratégies de ces communautés pour faire reconnaître leur culture sur la scène mondiale, pour en conserver la propriété morale et pour en contrôler la représentation dans les médias. Depuis trois décennies, des délégations « indigènes " originaires de différents États se réunissent régulièrement aux Nations Unies à Genève pour établir une déclaration universelle de leurs droits. Celle-ci a été approuvée en juin 2006 par tous les pays à l'exception du Canada et de la fédération de Russie. Barbara Glowczewski nous fait également part de ses réflexions concernant la place de l'ethnologue au sein des sociétés qu'il étudie. Son analyse des rituels est intéressante : la création de ces derniers par les communautés aborigènes aurait pour fonction de digérer les conflits historiques et leur disparition représenterait la perte d'un outil indispensable d'intervention sur le monde.

Les quatre premiers textes montrent comment les Aborigènes réinterprètent le passé en se servant de leurs propres concepts de piste du Dreaming (p. 15). Stéphane LacamGitareu aborde le problème du nomadisme face à la sédentarité dominante du peuple australien. Il nous montre d'une part comment la déchirure des jeunes Aborigènes, entre deux mondes, pousse ceux-ci à trouver de nouveaux réseaux d'alliance et d'errance, et d'autre part comment la christianisation et la redistribution des droits fonciers entraînent une nouvelle conception de la notion de territoire et provoquent parfois des conflits entre communautés. Il constate que la recrudescence des activités cérémonielles dans les années 1970 coïncide avec le début de la période d'ouverture faite aux Aborigènes par l'administration australienne. Un phénomène similaire s'est produit en Papouasie après l'indépendance en 1975. Jessica De Largy Healy explore comment la communauté des Aborigènes yolngu essaie de réinvestir les données de son passé en collaborant avec les chercheurs, les anthropologues et les conservateurs de musée pour la création d'une base de données des éléments de leur culture matérielle. L'auteur nous montre comment ce centre de savoirs indigènes contribue à revitaliser la culture en développant une nouvelle stratégie de communication. Les recherches dans les archives photographiques et sur les objets ethnographiques du monde entier permettent aux Yolngu de se réapproprier leur passé. Jessica De Largy Healy donne l'exemple de la collection de peintures collectée par Karel Kupka et conservée aujourd'hui au musée du quai Branly. Certaines de ces œuvres, réalisées par Tom Djäwa, témoignent du rôle politique décisif que cet artiste joua jadis dans les contacts avec l'administration australienne. Nous n'avons pas été convaincus par l'article d'Anke Tonnaer, qui tente de démontrer comment un groupe de femmes aborigènes a réussi à s'approprier les rôles dévolus habituellement aux hommes dans une danse intitulée Aeroplane dance. Les raisons structurelles propres à l'organisation sociale des groupes concernés par ce rituel n'ont pas été présentées avec suffisamment de précision pour expliquer cette innovation féminine dans les relations de genre. Martin Préaud utilise deux exemples de mises en scène réalisées par Andrish Saint-Clare avec des communautés aborigènes - "dans l'"esprit" d'un partage de pouvoir au sein d'une coproduction où les significations sont négociées au niveau formel des traditions » - en tenant compte de certaines contraintes de départ comme: «Faire entendre la voix 
propre des groupes en présence tout en les rendant intelligibles à un public non averti. »

5 Les trois textes suivants concernent plus particulièrement l'action des artistes aborigènes hors de l'Australie. Arnaud Morvan analyse leur présence en France. Il passe en revue les diverses manifestations artistiques qui ont été présentées depuis un quart de siècle au musée d'Art moderne, au musée en Herbe, au centre Georges-Pompidou, à Montpellier, au musée des Arts africains et océaniens, à Grenoble, à l'Unesco, à La Villette et au musée du quai Branly. Il expose les diverses stratégies visant à prendre le contrôle du discours produit sur leur propre culture, trop souvent confisqué par des étrangers plus ou moins bien intentionnés à leur égard. Selon Barbara Glowczewski, certains artistes disent que les voyages de leurs peintures dans les grandes capitales mondiales sont une manière de diffuser les chemins du rêve à travers la planète (p. 28). Géraldine Leroux s'intéresse à la production et à la médiation des arts aborigènes contemporains dans l'État du Queensland. Elle montre comment les artistes qui travaillaient avec les nouveaux médias telles la photographie et la vidéo, ou dont la production faisait plus référence à l'art occidental, ont été évincés du marché de l'art contemporain par le système dominant car ils ne correspondaient pas au concept à la mode de l'Aborigène présentant un rapport évident avec sa tradition ancestrale. La réaction à cette censure de l'industrie artistique étatique, majoritairement dominée par des acteurs non aborigènes, fut la création d'espaces alternatifs : coopératives, galeries, sites virtuels gérés par les jeunes artistes aborigènes. Les tactiques urbaines employées par ces derniers montrent qu'ils n'entendent faire aucun compromis, qu'ils cherchent à contrôler entièrement la présentation et la promotion de leur création, et souhaitent devenir pleinement des agents de leur histoire. Wayne Jowandi Barker est le seul " indigène" à s'exprimer dans cet ouvrage. Il est l'auteur de plusieurs films et compositeur-interprète de musique contemporaine, rock ou jazz ayant pour base les sonorités et la spiritualité de ses ancêtres. Il conte de façon très claire l'histoire de ses nombreuses expériences artistiques en Europe depuis le début des années 1990 et fait part de ses réflexions, exprimant quelques idées fortes de la jeunesse aborigène, dont la principale est de retrouver la fierté et le respect de soi. Il écrit ainsi : "Célébrer ce que notre identité indigène signifie pour nous, en l'exprimant par différentes formes d'art, insuffle de la vie dans nos esprits [...]. Cela réveille l'esprit qui est en nous et apaise les anciens qui veillent sur nous, heureux de voir que nous n'avons rien oublié » (p. 182). Son combat, comme celui de ses proches, revient à promouvoir lui-même sa culture à travers le monde sans passer par les fourches caudines de ceux qui ont asservi son peuple depuis plus de deux siècles. Aux lecteurs de méditer sa conclusion : « À quoi sert de présenter sa culture à un public international s'il n'y a pas d'engagement mutuel, d'échange réciproque? »(p. 194)

6 Les festivals culturels servent de terrain d'analyse dans les trois premiers textes de la seconde partie de l'ouvrage. Barbara Glowczewski et Rosita Henry démontrent comment la petite république de Palau, de vingt mille habitants, a réussi à accueillir les trois mille participants de vingt-huit pays océaniens au cours du neuvième festival des Arts du Pacifique en 2004 en mettant en œuvre sa seule organisation communautaire fondée sur un concept d'hospitalité traditionnelle, développée en l'occurrence par les femmes. Cette manifestation à permis à ce jeune État, qui a un droit de vote à l'ONU, de renforcer ses liens avec les autres États du Pacifique pour mieux résister aux pressions des grandes puissances dans son futur choix de libre association avec les États-Unis. Wolfgang Kempf montre comment le groupe des Banaban, originaire d'une petite île de 
Kiribati mais déplacé dans l'île fidjienne de Rabi par l'administration coloniale anglaise, a réussi à se servir de la politique d'authenticité prônée par les organisateurs du premier festival des Arts du Pacifique Sud à Fidji en 1971 pour réaliser ses propres objectifs politiques et se faire reconnaître comme une communauté à part entière. Jari Kupiainen présente le premier festival des Arts et de la Culture mélanésienne (Spirit bilong Melanesia), qui eut lieu en 1998 à Honiara, capitale des îles Salomon, tout en réfléchissant au concept local de kastom, bien éloigné du mot anglais custom. Il constate que la majorité des spectacles formulaient dans leur interprétation une évolution de «la sauvagerie primitive» vers une «modernité radieuse» dominée par le christianisme. Mais il reconnaît aussi que la majorité des groupes venaient juste d'être constitués pour la circonstance afin de faire revivre les traditions ancestrales mises à mal par le développement du christianisme dans la région depuis un siècle.

7 La multiplication des festivals culturels régionaux dans l'aire Pacifique, comme ceux des îles Marquises, de Rapa Nui (île de Pâques), de Mont Hagen et de Goroka, en Papouasie-Nouvelle-Guinée, ainsi que le Heiva à Tahiti, concerne des manifestations où se joue l'avenir culturel des communautés océaniennes. Elles sont l'occasion de nombreux échanges qui rapprochent les communautés, jadis séparées par les administrations coloniales ou par leurs propres traditions, et débouchent sur la création d'un nouvel espace politico-culturel. L'impact du festival Melanesia 2000, pensé par Jean-Marie Tjibaou en Nouvelle-Calédonie, a été à l'origine d'un renouveau de la conscience et de la fierté du peuple kanak et fut une prémisse à la création du désormais célèbre centre culturel de Nouméa, qui porte le nom de ce leader charismatique.

8 Les deux textes suivants relatent deux combats de peuples autochtones pour conserver leur identité au sein d'un monde hostile à leur culture. D'un côté, Alexandre Soucaille montre comment la communauté adivasi, vivant au sein de l'État indien du Jharkland et organisée en diverses associations internationales comme l'Alliance of the Indigenous Tribal Peoples of the Tropical Forests, a réussi à contourner les politiques néocoloniales des États-nation. De l'autre, Dominique Samson Normand de Chambourg présente un corpus de prières chamaniques associées au cycle rituel des jeux de l'Ours chez les Khanty de Sibérie, convertis depuis le début du xvIII ${ }^{\mathrm{e}}$ siècle à la religion chrétienne orthodoxe. La perpétuation de ce rituel semble avoir permis à cette communauté de conserver son identité jusqu'à nos jours malgré les rudes coups portés par le régime soviétique.

9 Au terme de cette somme de points de vue, Rosita Henry récapitule les idées fortes exprimées par chacun des auteurs sur le thème commun de cet ouvrage et conclut ainsi : « Ce livre témoigne de notre engagement à continuer de travailler d'arrache-pied à une anthropologie de la décolonisation. » Un livre à lire absolument par tous ceux qui s'intéressent à l'avenir des communautés autochtones et tout simplement à l'avenir de la communauté mondiale. 


\section{AUTEURS}

\section{CHRISTIAN COIFFIER}

christian.coiffier@quaibranly.fr 